\title{
LA DIGNIDAD DE LA PERSONA HUMANA EN SANTO TOMÁS DE AQUINO. UNA LECTURA MORAL ACERCA DE LA ANCIANIDAD ${ }^{1}$
}

\begin{abstract}
Mg. Jean Paul Martinez Z.*
La dignidad de la persona humana en santo Tomás de Aquino se funda en los aspectos ontológicos y morales, concebidos desde su comprensión como unidad sustancial de alma y cuerpo. Las facultades del alma, inteligencia y voluntad, posibilitan la libertad humana, base desde la cual se concibe la dignidad. Elementos que justifican en la persona del anciano una dignidad natural, según su naturaleza racional y libre, y una especial dignidad moral, ligada a la búsqueda de los fines últimos, en particular, en las últimas etapas de la vida. El análisis de los conceptos en cuestión hará posible una lectura moral acerca de la importancia de la ancianidad en la sociedad, fundamental para la defensa de su cuidado y respeto.
\end{abstract}

Palabras clave: dignidad, persona, ancianidad, moral, ontología.

\section{THE DIGNITY OF THE HUMAN PERSON IN SAINT THOMAS AQUINAS. A MORAL READING ON OLD AGE}

\begin{abstract}
According to Saint Thomas Aquinas, the dignity of the human person is based on ontological and moral aspects, as conceived by understanding it as the substantial unity of body and soul. The faculties of the soul, intelligence and will, make human freedom, the basis on which dignity is conceived, possible. These elements justify a natural dignity in the elderly person, in accordance with their rational and free nature, and a special moral dignity, linked to the pursuit of the final ends, especially in the last stages of life. The analysis of the concepts under discussion will allow a moral reading regarding the significance of old age in society, which is fundamental for their protection and respect.
\end{abstract}

Keywords: dignity, person, old age, moral, ontology.

1 En señal de agradecimiento a mis abuelos Carlos Martínez y María Miranda que con cariño y esfuerzo estuvieron siempre presentes en nuestra infancia.

*Pontificia Universidad Católica de Valparaíso- Universidad Santo Tomás- Conicyt, Valparaíso, Chile. Correo electrónico: jean.martinez.z@mail.pucv.cl 

$-$

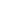




\section{Introducción}

EL PRESENTE ESTUDIO BUSCA INDAGAR Y COMPRENDER la especial dignidad de la persona del anciano a partir de la filosofía de santo Tomás de Aquino. La dignidad de la persona anciana se encuentra fundada en dos aspectos: su dignidad natural ${ }^{2}$, propia de su naturaleza racional y libre ${ }^{3}$, y la dignidad moral $^{4}$, que comprende la experiencia y libertad de perseguir los bienes superiores. Ambos aspectos representan las bases para una reflexión en torno a la dignidad del anciano en nuestros tiempos, en particular, para su análisis frente a los desafíos éticos que presenta su estudio en la sociedad.

Las motivaciones que nos conducen a indagar la dignidad de la persona del anciano son: primero, el desarrollo de una reflexión que promueva la igualdad e importancia de los ancianos en la sociedad. Segundo, reconocer la dignidad humana en todas las etapas de la vida, particularmente del anciano como aspecto central en la búsqueda de la felicidad y la paz. Tercero, reconocer el ejemplo social de los ancianos dentro del ámbito familiar y comunitario. Todos ellos aspectos centrales al momento de investigar la naturaleza del anciano y su valor social.

La metodología a emplear en esta investigación consiste básicamente en el análisis crítico e interpretación de las fuentes ${ }^{5}$ primarias, principalmente la Suma Contra Gentiles (1259-1265), Suma Teológica (1268-1272), Comentario a la Política de Aristóteles (12691272) y los Comentarios a la Ética de Aristóteles (1271-1272), mediante el análisis de dichos textos en su edición crítica.

La dignidad del anciano genera, en nuestros tiempos, un sinnúmero de interrogantes ${ }^{6}$ y problemáticas, especialmente aquellas que dicen relación con su análisis ontológico y

2 “Nam dignitas absolutum est, et ad essentiam pertinent". TomÁs De Aquino, Suma Teológica, Obras completas, traducción y notas de Barbado Viejo, Francisco, edición bilingüe, BAC, Madrid 1957. I, q. 42, a. 4, ad 2. En adelante $S$. Th.

3 "Libertas arbitrii ad dignitatem hominis pertinent". S. Th., I, q. 59, a. 3, sed contra.

4 Cfr. S. Th., II-II, q. 63, a. 2, corp.

5 Fechas tentativas entregadas en el catálogo de las obras de Tomás de Aquino en Torrell, Jean-Pierre, Tommaso D'Aquino, l'uomo e il teologo, Edizioni Piemme Theologica, Roma, 1994, pp. 369-401.

6 El hombre contemporáneo, frente al vértigo de la producción y el consumismo, parece sustituir en forma sistemática los valores del ser por el tener. Pareciera que el objetivo que determina su conducta es el que atañe a la satisfacción de las necesidades relativas al bienestar material y personal, distantes al bien común. De este modo, se busca una calidad de vida que persigue en forma exclusiva el bienestar económico y físico, lejos todavía de responder a las cuestiones relativas al bienestar interior, es decir, la búsqueda de una existencia en armonía consigo mismo y con quienes le rodean. El mito del crecimiento indefinido se ha distanciado del desarrollo sostenible con insospechadas consecuencias para las relaciones interpersonales, incluso para la sobrevivencia de la propia especie humana. Cfr. JABARES, Mario, "El valor de la vida humana. Una aproximación desde la Antropología", Studium, 49-1, pp. 41-76, pp. 52-53. 
moral. Disciplinas fundamentales para un estudio que reconozca su dignidad desde la libertad, premisa fundamental en la búsqueda de los fines últimos y universales sobre los cuales descansa la felicidad ${ }^{7}$. Por lo tanto, una defensa de la libertad del anciano que rescata la importancia de su cuidado y respeto promueve la justicia en la sociedad a través de la búsqueda de su bienestar fundado en su natural dignidad.

Según lo antes expuesto, el objeto del presente estudio buscará reconocer la naturaleza y alcances de la dignidad del anciano en Santo Tomás. Desafío importante para el respeto del anciano, junto al reconocimiento de su aporte al crecimiento moral de la sociedad ${ }^{8}$. Objetivo a desarrollar mediante el análisis de las siguientes temáticas: primero, persona humana en Santo Tomás de Aquino. Segundo, comunidad política. Tercero, la justicia y sus tipos. Cuarto, fundamentos de la dignidad humana en la ancianidad. Y, finalmente, la dignidad del anciano en la comunidad política. El análisis progresivo de estos conceptos posibilitará nuestro acercamiento al problema a investigar y nos permitirá reconocer la naturaleza de la dignidad del anciano para una fundamentación que promueva su importancia en la sociedad.

\section{Persona Humana}

La persona humana y su naturaleza en Santo Tomás, comprendida como sustancia individual de naturaleza racional ${ }^{9}$ y unidad sustancial de alma y cuerpo ${ }^{10}$, es analizada en el Tratado sobre el Hombre al inicio de la Suma Teológica. El concepto de persona posibilita la comprensión y estudio de la dignidad y, particularmente, de la persona del anciano. Acerca del concepto de persona conviene admitir lo siguiente.

En primer lugar, que el autor acoge y acepta la definición de persona ${ }^{11}$ de Boecio, expuesta en la Suma Teológica I, q.29, a.4 como: substancia individual de naturaleza racional $^{12}$. Según Santo Tomás, el término persona es: primero, una substancia completa, es decir, tiene una naturaleza completa, por esto el alma separada del cuerpo individual no es persona: "El alma forma parte de la especie humana, y por esto, aunque esté separada, como por naturaleza continúa siendo unible al cuerpo, no se la puede llamar substancia individual en el sentido de hipóstasis o substancia primera""13.

Segundo, que el término individual reconoce que persona es una sustancia primera, que subsiste en un particular. En el caso de la persona tenemos una sustancia primera

\footnotetext{
"Praeterea, beatitudo, sive felicitas, est praemium virtutis". S. Th., I, q. 26, a. 1, ob. 2.

Cfr. S. Th., I-II, q. 95, a. 3, corp.

Cfr. S. Th., I, q. 29, a. 4, corp.

10 Cfr. S. Th., I, q. 76, a. 1, corp.

1 En adelante el término persona se referirá en sentido restringido a la persona humana.

12 “Substantiam individuam rationalis naturae”. S. Th., I, q. 29, a. 4, corp.

13 "Quod anima est pars humanae speciei: et ideo, licet sit separata, quia tamen retinet naturam unibilitatis, non potest dici substantia individua quae est hypostasis vel substantia prima”. S. Th., I, q. 29, a. 1., ad 5.
} 
que no se sustenta en ningún otro sujeto y posee un modo particular de existencia. Si nos referimos a alguien, por ejemplo Sócrates, tenemos en este enunciado un sujeto que representa una sustancia primera, con su particular modo de ser sobre el cual recae toda su existencia. Según Santo Tomás, el concepto de individual añade a la sustancia al eliminar su consideración universal ${ }^{14}$.

Tercero, que por su diferencia específica se reconoce como naturaleza racional, ya que se entiende que la persona humana es capaz de obrar según un determinado fin. La diferencia específica en la definición de persona de Boecio implica que el hombre posee una razón ${ }^{15}$, facultad que permite conocer las esencias o formas desmaterializadas de las cosas (intus legere: leer dentro), y una voluntad o apetito racional, facultad por la cual se quiere o desea aquello que se conoce como objeto, según Santo Tomás: "entre todas las partes del hombre, el entendimiento es el motor superior, pues el entendimiento mueve al apetito, proponiéndole su objeto, al apetito racional que es la voluntad"16.

En segundo lugar, el autor expone la esencia de la persona humana, en la Suma Teológica I, qq.75-89, desde su estudio de las dimensiones formal y material del hombre, es decir, desde su concepción como unidad sustancial de alma y cuerpo ${ }^{17}$. Según Santo Tomás: "por lo tanto, este principio en virtud del cual primeramente entendemos, llámase entendimiento o alma intelectiva, es la forma del cuerpo humano"18. La relación entre estos dos elementos, determinada por los aspectos intelectivos, nos permite reconocer los estatutos ontológicos y operativos ${ }^{19}$ del ser humano, bases para las ulteriores reflexiones

14 Cfr. S. Th., I, q. 29, a. 1, ad 2.

15 Es interesante revisar la síntesis que realiza Brennan acerca de la "naturaleza racional" de la persona: "El hombre es una sustancia capaz de pensar y querer. Por tanto, es una persona por ser subsistencia de un ser capaz de conocer y amar de un modo intelectual y de decidir por sí mismo el fin de sus acciones. Ningún animal, ni planta u otro supuesto inferior pueden ser llamados persona, careciendo, como carecen, de naturaleza racional. El hombre es un agente libre. Es, pues, un ser con derechos y responsabilidades especiales. Tiene un destino que no puede compartir con ninguna otra criatura. A pesar de todo, únicamente tiene el mínimo de requisitos necesarios para ser admitido en la noble categoría de persona. Es una sustancia intelectual, aunque de clase ínfima”. Brennan, Robert, Psicología Tomista, trad. de Villacorta, Efrén, Aguilar, Madrid, 1959, p. 307.

16 "Inter omnes autem hominis partes, intellectus invenitur superior motor: nam intellectus movet appetitum proponiendo ei suum obiectum; appetitus autem intellectivus, qui est voluntas". Tomás De Aquino, Suma Contra Gentiles, Obras completas, traducción y notas Robles Carcedo, Laureano OP y Robles Sierra, Adolfo OP, edición bilingüe, BAC, Madrid, 1967, III, c.25. En adelante $S C G$.

17 Uno de los aspectos importantes desde los cuales se erige la comprensión de Santo Tomás acerca de la persona se encuentra ligada a la importancia de su consideración como unidad sustancial: "Questo può essere espresso anche dicendo che l'espressione forma dat esse, principio ontologico che adesso gesta nuova luce sul costitutivo formale della persona umana e la sua unità, e che diverrà uno degli assi fondamentali di ogni antropología cristiana, permanentemente illuminata dalla metafísica dell'essere". MARTínEZ, Joan, "Forma dat esse come principio fondamentale dell'ontologia della persona di Tommaso d Aquino", Angelicum, 86-3, pp. 669-688, p. 673.

18 "Hoc ergo principium quo primo intelligimus, sive dicatur intellectus sive anima intellectiva, est forma corporis”. S. Th., I, q. 76, a. 1, corp.

19 El análisis filosófico en torno a la persona promueve una discusión que no excluye sus aspectos biológicos sino a estos adhiere la reflexión en torno a sus motivaciones e inquietudes relacionadas con su sentido y finalidad: "In virtù dell'unità esistenziale unica della persona umana spiega sia le funzioni biologiche sia le capacità superiori. L'azione piú adatta alla natura umana consiste nel darsi le finalità en el scegliere i mezzi; in ciò consiste la libertà con la quale il circuito biologico si rompe e rimane aperto". MARTínez, J., op. cit., p. 675. 
en torno a su dignidad y moral ${ }^{20}$. En resumen, podemos destacar, según Ugarte, que: “el individuo o supuesto de naturaleza racional se llama persona para connotar la dignidad especialísima que le confiere la naturaleza racional, al permitirle poseerse a sí mismo por el conocimiento intelectual y el amor" 21.

\section{La comunidad política}

En las diversas etapas de la vida, la persona se halla íntimamente ligada a la sociedad, desde donde se constituye su perfección natural y la búsqueda de su felicidad ${ }^{22}$. Los problemas asociados con su bienestar se encuentran en directa relación con la sociedad a la cual pertenece, donde la justicia es el medio necesario para reestablecer el orden del individuo al bien común, fin de la comunidad política ${ }^{23}$.

La relación entre los individuos, según Santo Tomás, se desarrolla en la comunidad política, responsable del orden de los sujetos al bien común ${ }^{24}$, según el autor: "la voluntad de un individuo no es recta queriendo el bien particular si no lo refiere, como a su fin, al bien común" 25 . El bien común conviene al sujeto por dos motivos: primero, porque el bien de la persona no puede darse sin el de la sociedad; segundo, ya que es importante que la parte se ordene al todo, por cuanto es necesaria la prudencia del bien singular frente al bien de la multitud ${ }^{26}$.

La comunidad política, sociedad que reúne a las sociedades, ha de promover y difundir el bien, premisa fundamental para la realización y felicidad de todos los individuos en virtud de su nobleza y dignidad. Según lo anterior, la comunidad política debe tener por fin a todos sus individuos, otorgando los medios adecuados para que logren su realización. Dentro de este ámbito reconocemos que el bien común es el mayor de todos los bienes. Según Santo Tomás: "si toda comunidad se ordena a un bien, es necesario que aquella comunidad que sea la principal sea la que en mayor medida conecte al bien principal entre todos los bienes humanos" 27 . Se sostiene que del bien principal participan muchos, motivo por el cual se concibe un bien como político, esto es, de interés para toda la polis (ciudad).

20 Cfr. S. Th., I, q. 99, a. 4, corp.

21 Ugarte, José, El derecho de la vida, el derecho a la vida Bioética y Derecho, Editorial Jurídica de Chile, Santiago, 2006, p. 74.

22 Cfr. S. Th., I-II, q. 4, a. 8, corp.

23 "Dicit enim, in $V$., quod legalia iusta dicimus factiva et conservativa felicitatis et particularum ipsius, politica communicatione, perfecta enim communitas civitas est, ut dicitur in I Pol.”. S. Th., I-II, q. 90, a. 2, corp.

24 Cfr. S. Th., I-II, q. 21, aa. 2 y 4.

25 "Non est autem recta voluntas alicuius hominis volentis aliquod bonum particulare, nisi referat illus in bonum commune sicut in finem". S. Th., I-II, q. 19, a. 10, corp.

26 Cfr. S. Th., II-II, q. 47, a. 10, ad 2.

27 "Si omnis communitas ordinatur ad bonum, necesse est quod illa communitas quae est maxime principalis, maxime sit coniectatrix boni quod est inter omnia humana bona principalissimum”. Thomae Aquinatis, In libros politicorum Aristotelis Expositio, Marietti, 1951, I, Lectio $1 \mathrm{n}^{\circ}$ 11. En adelante In Pol. Traducción al español en Widow, José Luis, Introducción a la ética, Globo, Santiago, 2009, p. 72. 
La distribución del bien político necesita de una estructura comunitaria que permita que todas las personas sean consideradas: "De esta manera la comunidad política es la principalísima. Por lo tanto, es la que conecta el bien principal entre todos los bienes humanos, pues tiende al bien común, que es mejor y más divino que el bien de uno" ${ }^{28}$. La comunidad política, entonces, será el medio por el cual se ha de distribuir el bien del cual todas las personas participan y su perfección dependerá de la ordenación de la misma comunidad hacia el bien común ${ }^{29}$.

Santo Tomás establece que la inclinación natural al bienestar reconoce la necesaria relación entre felicidad y suficiencia de bienes materiales. Según el autor: "la indigencia es contraria a la razón de la felicidad, que requiere la suficiencia"30. La búsqueda de la virtud y la contemplación del fin último son, para Tomás de Aquino, resultado también del bienestar integral humano considerado desde su comprensión del sujeto como unidad sustancial de cuerpo y alma. Desde la anterior concepción humana se comprende que los bienes relativos al cuerpo son fundamentales para el crecimiento del espíritu, sobre todo aquellos que nos conducen al encuentro con nuestra felicidad y la de quienes nos rodean. No es posible una sociedad con individuos que busquen el bien común si estos han sido alejados del mismo por la sociedad y privados de los medios necesarios para lograr su bienestar $^{31}$.

Razón por la cual se destaca la importancia de la necesaria concordancia entre la ley ${ }^{32}$ y la felicidad común, que es también la plenitud de la comunidad política con el objeto de velar por la felicidad de las personas:

Y, como el último fin de la vida humana es la felicidad o bienaventuranza, como ya dijimos, es necesario que la ley mire principalmente a ese orden de cosas relacionadas con la bienaventuranza. Además, si la parte se ordena al todo como lo perfecto a lo imperfecto, y siendo el hombre individual parte de la comunidad perfecta, es necesario que la ley propiamente mire a aquel orden de cosas que conduce a la felicidad común ${ }^{33}$.

28 "Et sic ipsa communitas politica est communitas principalissima. Est ergo coniectatrix principalissimi boni inter omnia bona humana: intendit enim bonum commune quod est melius et divinius quam bonum unius". Idem. Traducción en Widow, J. L., op. cit., p. 72.

29 Cfr. Widow, J. L., op. cit., pp. 72-73.

30 "Alioquin remanebit indigentia, quod est contra rationem felicitatis, quae requerit sufficientiam". THOMAE Aquinatis, In decem libros Ethicorum Aristotelis ad Nicomachum Expositio, Marietti, Romae, 1949, IX, lectio $11, \mathrm{n}^{\circ}$ 1912. En adelante In Ethic. Traducción al español en García LóPEZ, Jesús, Los derechos humanos en Santo Tomás de Aquino, Eunsa, Pamplona, 1979, p. 110.

31 Cfr. In I Ethic., lectio $1, \mathrm{n}^{\mathrm{o}} 4$.

32 Cfr. S. Th., I-II, q. 90, a. 2, corp.

33 "Est autem ultimus finis humanae vitae felicitas vel beatitudo, ut supra habitum est. Unde oportet quod lex maxime respiciat ordinem qui est in beatitudinem. Rursus, cum omnis pars ordinetur ad totum sicut imperfectum ad perfectum; unus autem homo est pars communitatis perfectae, necesse est quod lex proprie respiciat ordinem ad felicitatem communem”. S. Th., I-II, q. 90, a. 2, corp. 
Bienestar que se sostiene, además, por la inclinación natural del hombre a vivir en dicha comunidad ${ }^{34}$. Para Santo Tomás, la felicidad del hombre se halla en la sociedad, por cuanto el hombre es un ser social; su perfección, por lo tanto, no puede ser distante de la comunidad política, y su orden es el mejor entre los asuntos humanos a través de la ley ${ }^{35}$.

\section{La Justicia y sus tipos}

La justicia será el medio que reestablecerá el orden al bien común y posibilitará la igualdad de derechos, según la dignidad humana. Por justicia, Santo Tomás comprende que: "se llama justo lo que según alguna igualdad corresponde a otro"36; "la justicia versa propiamente, como sobre peculiar materia, acerca de aquellas cosas que se refieren a otro" 37 y finalmente: "el nombre de justicia entraña igualdad, es de esencia el referirse a otro, porque nada es igual a sí sino a otro" ${ }^{38}$.

La justicia corresponde, por tanto, a una virtud asociada a ordenar aquellas cosas que le convienen a los individuos ${ }^{39}$. Santo Tomás comprende por objeto de la voluntad el bien racional proporcionado a ella ${ }^{40}$, por consiguiente, la voluntad persigue el bien supremo como fin último y el bien particular proporcionado al bien último: "la voluntad se adhiere al fin último, que es la bienaventuranza"41. La justicia posibilita una comunión social entre las personas, sobre todo por el cumplimiento de las leyes erigidas por los sujetos en la sociedad $^{42}$.

Respecto a los tipos de justicia nos encontramos: primero, la justicia general o legal inspirada en la ley natural que tiende a la concordancia de los actos humanos al bien común, denominada en nuestros tiempos justicia social ${ }^{43}$. Segundo, la ley particular divi$\operatorname{dida}^{44}$ en conmutativa, relación de justicia entre un individuo a otro ${ }^{45} \mathrm{y}$, distributiva, que comprende la relación de justicia del todo de la comunidad a sus partes, los individuos ${ }^{46}$.

La justicia general o legal, permite la ordenación de los bienes individuales al bien común, el cual es esencialmente el bien que ha de perseguir toda persona. Según el autor:

34 Vid. García López, J., op. cit., pp. 110-112.

35 Cfr. S. Th., I, q. 96, a. 4, corp.

36 "Dicitur esse iustum quod respondet secundum aliquam aequalitatem alteri”. S. Th., II-II, q. 57, a. 1, corp.

37 "Est autem iustitia circa ea quae ad alterum sunt, sicut circa propiam materiam". S. Th., II-II, q. 58, a. 1, corp.

38 "Cum nomen iustitiae aequalitatem importet, ex sua ratione iustitia habet quod sit ad alterum”. S. Th., II-II, q. 58 , a. 2, corp.

39 Cfr. S. Th., II-II, q. 58, a. 1, corp.

40 S. Th., I-II, q. 56, a. 6, corp.

41 "Ita voluntas ex necessitate inhaereat ultimo fini, qui est beatitudo". S. Th., I, q. 82, a. 1, corp.

42 Cfr. S. Th., I-II, q. 91, a. 3, corp.

43 Cfr. S. Th., II-II, q. 58, a. 5, corp.

44 Cfr. S. Th., II-II, q. 61, a. 1, corp.

$45 C f r . S$. Th., II-II, q. 61, a. 1, corp.

46 Cfr. idem. 
Como la parte, en cuanto tal, es del todo, síguese que cualquier bien de la parte es ordenable al bien del todo. Según esto, por lo tanto, el bien de cualquier virtud, ya ordene el hombre a si mismo, ya le ordene a otras personas singulares, es referible al bien común, al que ordena la justicia ${ }^{47}$.

Se ha expuesto, por consiguiente, que el bien de la persona no puede ser comprendido con independencia del bien de la sociedad, motivo por el cual la persona particular debe ser considerada en la distribución del bien según la justicia. El bien del todo ha de procurar el bien de la parte, por lo que se sostiene una cierta responsabilidad de la comunidad política frente a cuestiones relativas al cuidado y protección de los individuos.

La justicia entre personas, según su esencia y dignidad, admite a todos los individuos de la especie humana del mismo modo, incluso a los más débiles de la sociedad, como por ejemplo, los ancianos, quienes, según naturaleza, son dignos y tienen los mismos dere$\operatorname{chos}^{48}$ que los demás sujetos de su misma especie. La comunidad política ha de ser justa y promover la igualdad en la sociedad protegiendo a los más desvalidos, en particular, aquellos que no pueden lograr sin auxilio su personal bienestar e integración en la sociedad: entre estas personas se hallan los ancianos. Cuestión medular si comprendemos que la injusticia que afecta a una parte de la sociedad afectará tarde o temprano la estabilidad y desarrollo de la comunidad política en su conjunto.

\section{Fundamentos de la dignidad en la ancianidad}

La dignidad ${ }^{49}$, según el análisis de Santo Tomás, será considerada como un atributo esencial de la persona. La dignidad ${ }^{50}$ considerará: en primer lugar, la racionalidad de la persona: " puesto que es de gran dignidad subsistir en la naturaleza racional, a todo individuo de esta naturaleza se le llama persona"51. Lo anterior, según el autor, ya que las naturalezas intelectuales poseen mayor nobleza: "superan a las otras criaturas en perfección de naturaleza y en dignidad de fin. En perfección de naturaleza, porque solo las criaturas

47 "Pars autem id quod est totius est, unde et quodlibet bonum partis est ordinabile totius. Secundum hoc igitur bonum cuiuslibet virtutis, sive ordinantis aliquem hominem ad seipsum sive ordinantis ipsum ad aliquas alias personas singulares, est referibile ad bonum commune, ad quod ordinat iustitia”. S. Th., II-II, q. 58, a. 5, corp.

48 Cfr. S. Th., I-II q. 95, a. 4, ad 1.

49 El concepto de dignidad tiene su origen etimológico en el término griego $\alpha \xi \iota \sigma \gamma$, traducido por los latinos como dignitas, concepto vinculado a la honorabilidad de la persona según su comportamiento moral: "Así tradujeron los escolásticos, siguiendo el ejemplo de Boecio, la palabra axioma”. AbBagnano, Nicola, Diccionario de filosofía, trad. de Calderón, José Esteban, Fondo de Cultura Económica, México, 2007, p. 305.

50 La dignidad de la persona, según Santo Tomás, se basa fundamentalmente en Dios, dignidad que recibe como imagen de su creador. Cfr. S. Th., I, q. 92, a. 2, corp.

51 "Et quia magnae dignitatis est in rationali natura subsistere, ideo omne individuum rationalis naturae dicitur persona”. S. Th., I, q. 29, a. 3, ad 2. 
racionales tienen dominio de su acto, y se actúa libremente en sus operaciones" ${ }^{2}$. La razón, por consiguiente, posibilita la libertad como elemento propio del ser humano que lo distingue del resto de las criaturas, aspecto fundamental de su dignidad. En cuanto a la libertad : "Lo que tiene dominio sobre su acto, es libre en su obrar. Porque libre es el que es causa de sí mismo; y al contrario, lo que tiene necesidad de ser actuado por otro para obrar, está sujeto a servidumbre. Luego toda criatura, exceptuada solamente la intelectual, está sujeta a servidumbre" ${ }^{24}$. Según lo antes expuesto, la concepción de un ser capaz de ejecutar acciones libres será, en consecuencia, el rasgo distintivo y propio del hombre ${ }^{55}$.

En segundo lugar, podemos destacar que la dignidad también se funda en la naturaleza humana según su modo de existir ${ }^{56}$, que corresponde en la persona humana a la unidad sustancial de alma y cuerpo, relación determinada por el alma como forma sustancial de la materia ${ }^{57}$. La perfección del hombre radica, entonces, en la intrínseca unidad de estos dos elementos, según Santo Tomás: "No toda sustancia individual es hypostasis o persona, sino la que posee naturaleza específica completa. Por eso ni pueden ser llamadas hypostasis o personas la mano o el pie, ni tampoco el alma, que es una parte de la especie humana" ${ }^{58}$. Se entiende, de este modo, la importancia esencial de la unidad del alma y el cuerpo al momento de reconocer la naturaleza humana.

Según los motivos antes expuestos, por la naturaleza intelectual del hombre reconocemos su capacidad de conocer la verdad, ya que: "Así, pues, el fin del entendimiento es a la vez el fin de todas las acciones humanas. Mas el fin y el bien del intelecto es la verdad"59 y el obrar libremente para amar. La persona posee la capacidad de la consecución de sus fines, cuales son: conocer y amar ${ }^{60}$, fines posibilitados por la naturaleza racional del hombre que los identifica con la inteligencia y se dispone a la ejecución de los actos por la voluntad $^{61}$, caracteres en los que reconocemos la dignidad humana.

52 "Praecellunt enim alias criaturas et in perfectione naturae, et in dignitate finis. In perfectione quidem naturae, quia sola creatura rationalis habet dominium sui actus, libere se agens ad operandum”. SCG, III, c. 111.

53 Conviene destacar que, como primera aproximación, la dignidad de la persona humana recae en gran medida en su propia conciencia y responsabilidad frente a su propia libertad: "La dignità della persona risiede nella conscienza e nella sua libera responsabilità". Molinaro, Aniceto, "Riflessioni sulla Dignitatis humanae", Gregorianum, 89-4, pp. 806-820, p. 807.

54 "Quod dominium sui actus habet, liberum est in agendo, liber enim est qui sui causa est: quod autem quadam necessitate ab alio agitur ad operandum, servituti subiectum est. Omnis igitur alia creatura naturaliter servituti subiecta est: sola intellectualis natura libera est”. SCG, III, c. 112.

55 Vid. Melendo, Tomás, Dignidad humana y bioética, Eunsa, Pamplona, 1999, p. 111.

56 Vid. S. Th., III, q. 20, a. 1, ad 2.

57 Vid. Melendo, T., op.cit., p. 173.

58 "Quod non quaelibet substantia particularis est hypostasis vel persona: sed quae habet completam naturam speciei. Unde manus vel pes non potest dici hypostasis vel persona. Et similiter nec anima, cum sit pars speciei humanae”. S. Th., I, q. 75, a. 4, ad 2.

59 "Finis igitur intellectus est finis omnium actionum humanorum. Finis autem et bonum intellectus est verum". $S C G$, III, c. 25.

60 Cfr. SCG, III, c. 112.

61 “Actus personales rationalis creaturae sunt proprie actus qui sunt ab anima rationalis”. SCG, III, c. 113. 
Expuesto lo anterior, es de vital importancia reconocer que los aspectos ontológicos de la dignidad de la persona humana están intrínsecamente unidos a una moral del hombre ${ }^{62}$. De este modo, no tenemos dos posiciones separadas al momento de comprender y pensar el sujeto en la filosofía del autor medieval. Primero, ya que un vínculo entre la ontología y la moral reconoce que la concepción del bien moral es el bien metafísico por cuanto dependen de la voluntad libre ${ }^{63}$. Segundo, porque la concepción del hombre como unidad sustancial de alma y cuerpo comprende los aspectos racionales como determinantes en la búsqueda de la felicidad ${ }^{64}$ : "El fin último del hombre y de toda sustancia intelectual se llama felicidad o bienaventuranza; pues esto es lo que desea como fin último toda sustancia intelectual, y lo desea de por sí" ${ }^{65}$, fin al cual aspira el sujeto por medio del conocimiento y el amor $^{66}$.

Podemos establecer, según lo expuesto anteriormente, que la dignidad humana fundada en la naturaleza puede ser comprendida bajo dos aspectos fundamentales: primero, dignidad natural ${ }^{67}$, por cuanto toda persona es digna según su naturaleza racional ${ }^{68}$. Segundo, dignidad moral ${ }^{69}$, propia de las acciones del hombre ${ }^{70}$ en atención a las virtudes morales ${ }^{71}$, motivo por el cual una persona es digna mientras más virtuosos sean sus actos. En este aspecto la ancianidad posee una disposición, por la experiencia en el conocimiento y amor $^{72}$, hacia la dignidad moral posibilitada por la vida activa, que involucra obrar según su propia naturaleza, es decir, obrar en libertad mediante acciones externas que persigan la virtud y, por otro lado, mediante la vida contemplativa, que comprenderá aquellas acciones internas del hombre propias a su verdad y los fines últimos. Entre estos fines se hallan la sabiduría y el amor $^{73}$.

62 Una de las dificultades respecto a la separación entre moral y ontología es explicada por Leclercq del siguiente modo: "Pour lui donner un nom, qualifions cette tendance de 'moralisme'. Elle consiste à faire du mal une réalité distincte de l'ontologique. Ontologique veut simplement dire 'ce qui est'. Séparer la morale de l'ontologique, c'est la séparer de ce qui est et, par conséquent, du réel. Cette tendance qui se manifeste de façon plus ou moins radicale selon les écoles et les hommes, conduit à faire de la morale une conventiont et, finalement, à la nier". LeCleRCQ, Jacques, La philisophie morale de Saint Thomas devant la pensée contemporaine, J. Vrin, Paris, 1955 , p. 228.

63 Según Leclercq: "Le bien moral est le bien métaphysique, quoique le bien métaphysique ne soit pas le bien moral. Le bien moral est le bien métaphysique en tant que dépendant de la volonté libre”. Ibidem, p. 227.

64 Cfr. ibidem, pp. 227-228.

65 "Ultimus autem finis hominis, et cuiuslibet intelectuallis substantiae, felicitas sive beatitudo nominatur: hoc enim est quod omnis substantia intellectualis desiderat tanquam ultimum finem". SCG, III, c. 25.

66 Cfr. SCG, IV, c. 19.

$67 C f r . S$. Th., I, q. 42, a. 4, corp.

68 Cfr. S. Th., III, q. 2, a. 2, ad 2.

69 Cfr. S. Th., II-II, q. 63, a. 2., corp.

70 Cfr. S. Th. III, q. 20, a. 1, ad 2.

71 “Virtutes autem morales sunt quibus vires appetitivae perficiuntur ab obediendum rationi”. S. Th., I-II, q. 68, a. 8, corp.

72 Cfr. S. Th., I, q. 59, a. 4, ad 2.

73 Cfr. S. Th., I-II, q. 69, a. 3, corp. 
La dignidad del anciano admitirá, por tanto, la experiencia como factor determinante en la apreciación de la vejez a causa de una determinada disposición a los bienes superiores, representada por la búsqueda de la paz y la concordia ${ }^{74}$. La experiencia de vida del anciano, en la que se incluyen sus errores y aciertos, admite una mayor cercanía hacia una vida moral, especialmente porque las vivencias de las propias dificultades acumuladas en la vida le permiten su encuentro consigo mismo y su propio bienestar espiritual.

\section{La dignidad del anciano en la comunidad política}

La comprensión tomista de la dignidad de la persona permite, por tanto, el desarrollo de una lectura analítica de la naturaleza moral del hombre, análisis que conlleva una comprensión en torno a la persona humana en nuestros tiempos, lejana de posturas vinculadas a la dignidad natural ${ }^{75}$. El estudio y análisis de los aspectos ontológicos y morales de la dignidad de la persona humana parecen cada vez más necesarios ${ }^{76}$, mientras más alejada se encuentra la sociedad del bien común:

Siendo pues, el hombre parte de la ciudad, es imposible que un individuo sea bueno si no guarda la debida proporción con el bien común; y el todo no puede ser perfecto si sus partes no son proporcionales a él. Por eso es imposible que el bien común de la ciudad resplandezca si los ciudadanos, al menos los encargados de gobernar, no son virtuosos ${ }^{77}$.

Por otro lado, ya en nuestros tiempos, la sociedad parece representar inclinaciones cada día más inquietas por la búsqueda incesante del bien individual ${ }^{78}$. Múltiples situaciones nos llevan a cuestionar el lugar que ocupan en la sociedad aquellos más débiles y desprotegidos; entre estos, los ancianos, aquellos que con mayor dificultad acceden a bienes básicos para subsistir. Ajenas a la justicia, las personas ven que su dignidad ${ }^{79}$ no es considerada, es decir, los más débiles se ven marginados del bienestar material, cuestión que distancia al hombre de su propia felicidad.

La dignidad natural de la persona humana, junto a las obligaciones de la sociedad para su protección en todos las etapas de la vida humana, requiere una comprensión objetiva

74 Cfr. S. Th., I-II, q. 70, a. 3, corp.

75 Vid. CAmps, Victoria, Una vida de calidad, Ares y Mares, Barcelona, 2001, p. 116.

76 Vid. PalazZani, Laura, "Metafisica e bioetica: il concetto di persona?", Aquinas, 50-1, pp. 153-161, p. 157.

77 "Cum igitur quilibet homo sit pars civitatis, impossibile est quod aliquis homo sit bonus, nisi sit bene proportionatus bono communi: nec totum potest bene consistire nisi ex partibus sibi proportionatis. Unde impossibile est quod bonum commune civitatis bene se habeat, nisi cives sint virtuosi, ad minus illi quibus convenit principari". S.Th., I-II, q.92, a.1, ad 3.

78 Las ciencias y tecnologías actuales son cada vez más utilizadas en virtud de situaciones ajenas a las mismas enfermedades de las personas. Sobre el particular vid. los datos entregados por Lolas, Fernando (ed.), Dimensiones éticas de las regulaciones de salud, CBIED, Santiago, 2009, p. 99.

79 Vid. Carrasco, María, "Adam Smith y el relativismo”, Anuario filosófico, 47-1, pp. 179-204, p. 199. 
y justa, según el autor medieval: "dado que el hombre es por naturaleza un animal social, ya que su vida necesita muchas cosas que él no puede procurarse por sí solo, resulta obvio que forme parte naturalmente de alguna sociedad que le ayude a vivir bien" ${ }^{80}$. El trato justo a las personas y la solución de sus necesidades materiales básicas son esenciales para promover una sociedad que atienda a su fin más propio; en este caso, el acceso al bien común para todas las personas que conforman una sociedad, especialmente para los marginados y desposeídos, entre ellos los ancianos, los cuales con mayor dificultad acceden a los bienes considerados colectivos. En particular, los padres, que en edad avanzada difícilmente pueden abastecerse por sí mismos; según el autor: "se debe al padre lo que le corresponde, por algún título extrínseco. Por ejemplo, si está enfermo, que se le visite y asista; si es pobre, que se le sustente; y así otras cosas, incluidas en el deber de la sumisión o servicio" ${ }^{81}$.

Las temáticas antes expuestas dan cuenta de la necesidad de sólidos argumentos ${ }^{82}$ que orienten aquello que mejor convenga al respeto y cuidado de la dignidad del anciano ${ }^{83}$ : "La senectud da cierta excelencia; por eso a los ancianos se les debe reverencia y honor, según se lee: levántate ante la cabeza cana y honra la persona del anciano" ${ }^{\text {. E }}$ El estudio y análisis de su dignidad destaca, además, su importancia en la participación de la comunidad política respecto a la promoción de los bienes más importantes del ser humano, entre ellos el amor y el conocimiento. Los ancianos ${ }^{85}$ son también fuentes de afecto y sabiduría en las familias y, sobre todo, de experiencia, fundamentales para el encuentro de la so-

80 "Quod quia homo naturaliter est animale sociale, utpote qui indiget ad suam vitam multis, quae sibi ipse solus praeparare non potest; consequens est, quod homo naturaliter sit pars alicuius multitudinis, per quam praestetur sibi auxilium ad bene vivendum". In I Ethic., lectio 1, $\mathrm{n}^{\circ} 4$. Traducción al español en García LóPEZ, J., op. cit., p. 111.

81 "Per accidens autem aliquid debetur patri quod decet eum accipere secundum aliquid quod ei accidit, puta, si sit infirmus, quod visitetur, et eius curationi intendatur: et si sit pauper, quod sustentetur; et sic de aliis huiusmodi, quae omnia sub debito obsequio continentur". S. Th., II-II, q. 101, a. 2, corp.

82 Acerca del particular cabe destacar la importancia de una fundamentación que promueva una debida comprensión de la dignidad humana: "la pregunta primera es si, desde la dignidad de la persona, se puede exigir un respeto incondicionado que señale el sentido y los límites del dominio técnico del hombre con el hombre. La bioética debe encontrar un principio unificador frente a las escisiones entre ciencia, técnica y ética, entre dominio técnico y dominio humano. Este principio debe partir de la visión integral de la persona humana, en todas sus dimensiones, valores y exigencias". LoLAs, F., op. cit., p. 93.

83 Cabe destacar una importante reflexión realizada por el historiador norteamericano David Fisher, acerca del tema del cuidado de los ancianos a finales del s. XIX: “(los viejos) recibían respeto sin afecto, eran honrados sin devoción y venerados sin amor. Con el paso del tiempo la edad avanzada ganó sobre todo en el sentido de ser exaltada, es decir, fue más homenajeada y aún menos amada". Sin duda, esta temática muestra la desolación de muchos adultos mayores en nuestros tiempos, que no solo han dejado de ser amados sino también homenajeados". Callahan, David, Poner limites, los fines de la medicina en una sociedad que envejece, trad. de Mauri Mas, Assumpta, Triacastela, Madrid, 2004, p. 135.

84 "Senectus enim excellentiam quandam homini praestat, unde et senibus reverentia et honor debetur, secundum illud Lev. 19,32: coram cano capite consurge, et honora personam senis”. S. Th., II-II, q. 149, a. 4, ob. 1.

85 Según Basso: "puesto que hay obligación de cuidar y conservar la vida, también nos asiste el derecho de que nadie nos quite la posibilidad de vivir y de madurar para nuestro destino, posibilidad que no retorna". La valoración del cuidado está en directa relación con nuestro bienestar corporal. La recta aplicación de la justicia nos permite conservar aquello que consideramos más esencial al hombre, el derecho a la salud frente a las dificultades físicas que se experimentan a lo largo de nuestra vida. Dificultades que son parte esencial para el encuentro con nuestro destino y propia dignidad". BAsso, Domingo, Nacer y morir con dignidad, estudios de bioética contemporánea, Selare, Buenos Aires, 1990, p. 46. 
ciedad con el bien común. Santo Tomás, acerca del particular, nos dice que: "es necesario acatar el juicio de los expertos, de los ancianos o de los prudentes en sus enunciados no demostrables y en sus opiniones como en sus demostraciones" ${ }^{\prime 6}$.

El anciano ocupa una posición irremplazable en la sociedad. El carácter particular de la ancianidad nos muestra el atardecer de vida como un fenómeno propio de nuestra naturaleza asociada al saber por la experiencia ${ }^{87}$. Según las razones antes expuestas, Santo Tomás reconoce la importancia de la persona anciana y su lugar en la sociedad.

La experiencia adquirida a través de los años añade un valor a la dignidad de las personas mayores, según el cual el carácter esencial del ser humano que conoce y accede a la verdad lo lleva a profundizar en los aspectos morales mediante su particular vivencia de la vida activa y contemplativa. Actitud frente a las cosas que los muestra como fuente del sabiduría, a la cual la familia y la sociedad pueden recurrir muchas veces en búsqueda de respuestas para enfrentar las contingencias de la vida. El anciano y su dignidad se alzan como elementos fundamentales para el crecimiento moral de la sociedad, siempre que la comunidad política reconozca el bienestar de sus ciudadanos como condición propia para la paz ${ }^{88}$.

Según los motivos antes esgrimidos, un estudio que reconozca la dignidad de la persona humana en todas y cada una de sus distintas etapas, desde el pensamiento de Santo Tomás de Aquino, se erige como un medio fundamental para auxiliar la comprensión del hombre y su lugar e importancia en la sociedad, siempre en orden al bien común. Mientras las acciones de las personas estén orientadas al bien común, mayores serán las posibilidades del hombre para vivir una vida activa y contemplativa que los acerque a la felicidad ${ }^{89}$.

No obstante, dicha exigencia de vida no es posible en medio de la privación de los medios de subsistencia y bienes básicos para vivir, que en el caso de los ancianos impiden la tranquilidad de quienes con nostalgia piensan en sus tiempos de juventud, en los cuales podían por sí mismos proveerse de los bienes para su mantención. Dejar de lado el apoyo a los ciudadanos ancianos es ir en contra del fin mismo de la comunidad política:

La ciudad es una comunidad perfecta. Lo que se prueba porque, como toda convivencia entre los hombres se ordena a algo necesario para la vida, la comunidad perfecta será aquélla que se ordena a que los hombres tengan de modo suficiente todo lo que es necesario para la vida ${ }^{90}$.

86 "Oportet attendere expertorum et seniorum vel prudentum indemostrabilibus enuntiationibus et opinionibus, non minus quam demostrationibus". S. Th., I-II, q. 95, a. 2, ad 4.

87 Cfr. S. Th., II-II, q. 63, a. 3, corp.

88 Vid. In III Pol., lectio 3, $\mathrm{n}^{\circ} 366$.

89 Cfr. S. Th., I-II, q. 69, a. 3, corp.

90 "Quod civitas est commmunitas perfecta: quod ex hoc probat, quia cum omnis communicatio omnium hominum ordinetur ad aliquid necessarium vitae, illa erit perfecta communitas, quae ordinatur ad hoc quod homo habeat sufficienter quicquid est necessarium ad vitam". In I Pol., lectio 1, n 31. Traducción en Widow, J. L., op.cit., p. 73. 
Negar al anciano ${ }^{91}$ su respeto y cuidado es arrebatarle la opción de aceptarse a sí mismo, aceptación que tiene relevantes consecuencias para el encuentro del hombre consigo mismo. Reconocer la sabiduría y dignidad en la ancianidad nos permite tener presente la vital importancia del don de la vida en todas sus etapas. No es posible el olvido de la dignidad del anciano, por cuanto su olvido instala la distancia del hombre con su propia dignidad.

\section{Conclusión}

Se expresa, por tanto, que la dignidad de la persona humana se funda en los aspectos ontológicos y morales, concebidos desde su comprensión como unidad sustancial de alma y cuerpo en la cual las facultades del alma, inteligencia y voluntad, posibilitan la libertad humana, base desde la cual se concibe la dignidad. Posición que establece en la persona del anciano una dignidad natural, que proviene de su naturaleza racional y libre, y una especial dignidad moral, ligada a su disposición a obrar según virtudes morales superiores a las tendencias asociadas a los placeres de la sensibilidad.

De este modo, y por la libertad, la dignidad de la persona del anciano se fundará en su experiencia para amar y saber, bases de una vida activa y contemplativa para su encuentro con la felicidad. La comprensión de la dignidad del anciano facilita la defensa de su respeto, como asimismo el reconocimiento de su aporte al crecimiento moral de la sociedad.

Según lo expuesto en el presente estudio, la dignidad del anciano tendrá dos importantes consecuencias: primero, que la apreciación de la vejez consiste en su consideración como modelo social, determinada por su disposición a los bienes superiores mediante la búsqueda de la felicidad y la paz. Segundo, reconocer el valor de la dignidad natural del anciano como elemento propio para su respeto y cuidado en la sociedad.

Primero, que la dignidad del anciano representa la disposición humana a los bienes superiores, la felicidad y la paz, mediante su experiencia y ejemplo de vida. Posición opuesta al ritmo de los acontecimientos en estas últimas décadas, distante de la concordia y los últimos fines del hombre. La búsqueda de la felicidad a través del trabajo por el bien común no parece ser prioridad para el crecimiento moral en las personas y el de la sociedad en su conjunto.

Vemos, en nuestros tiempos, sucesivos eventos que parecen no respetar la dignidad humana y sus etapas, entre ellas la ancianidad, ni al ser humano en su general condición. La humanidad parece girar en torno a un crecimiento económico distante de la concordia

91 "Philosophus dicit, in II Rhet: Homines miserentur super illos qui sunt eis coniuncti et similes: quia per hoc fit eis aestimatio quod ipsi etiam possint similia pati. Et inde est etiam quod senes et sapientes". S. Th., II-II, q. 30, a. 2, corp. 
del sujeto consigo mismo y la estabilidad de las partes que conforman la sociedad. Dentro de este contexto, el estado de la ancianidad instala el problema de la búsqueda del bien final. Los errores y aciertos de las personas mayores a lo largo de la vida permiten su asertividad al momento de juzgar distintas cuestiones de la vida social. Juicios que sirven de consejos a quienes se extravían muchas veces en la confusión entre el éxito y la felicidad. Por otro lado, las dificultades físicas añaden un relevante elemento a considerar en su camino hacia el bien final. El sufrimiento por las enfermedades vuelve a los ancianos más sensibles a la valoración de las cosas sencillas de la vida, situación que dispone su búsqueda y necesidad de concordia y paz.

El anciano, además, aporta a la sociedad en su comprensión de los bienes superiores mediante su ejemplo de vida. Basta recordar la tenacidad con la cual muchos de ellos enfrentan las más diversas y duras circunstancias familiares, siendo para estas apoyo moral e, inclusive, material. Múltiples son los ancianos que, ya abuelos, trabajan y auxilian a nietos e hijos cuando por enfermedad estos últimos no pueden mantenerse a sí mismos ni a sus familias, ejerciendo su cuidado con ternura y afecto. Su testimonio es, sin lugar a dudas, ejemplo de vida y lucha por los fines últimos del hombre.

Segundo, otra consecuencia a considerar es que la dignidad natural del anciano nos dispone a su respeto y cuidado en la sociedad. La naturaleza racional propia de todo ser humano posibilita la libertad del hombre para obrar según su fin, su realización y bienestar. Según lo anterior, se expone que la dignidad natural del hombre es transversal en todas sus etapas, incluyendo la ancianidad, cuestión fundamental para comprender los alcances de la vida humana y su debido cuidado y respeto en la comunidad política. Los ancianos son igualmente dignos que las personas de otras edades para buscar su felicidad.

La separación de los aspectos ontológicos y morales al momento de analizar la moral supone atentar contra el propio fin y dignidad humana. De este modo, todo esfuerzo por distanciar la libertad de una felicidad, según la virtud, constituye desconocer la naturaleza de la misma libertad. La dignidad natural del anciano tiene como consecuencia defender su cuidado y respeto, sobre todo en tiempos en que la desigualdad material gatilla la miseria moral entre quienes no poseen los medios básicos para sobrevivir. Los bienes materiales son fundamentales para el desarrollo y crecimiento moral del anciano. Una comunidad política que no persiga la paz y el bienestar de estos, como de todos los ciudadanos, atenta contra sí misma y se vuelve vulnerable al dolor y la injusticia. Por estas razones, una reflexión en torno a la dignidad del anciano posibilita una lectura moral de la persona humana en su integridad, acompañada del descubrimiento de la belleza de la vida y sus manifestaciones en todas las etapas del hombre, paso fundamental para acercarnos a nosotros mismos y nuestra humanidad, siempre inquieta por el encuentro final con la felicidad y la paz.*

* Artículo recibido: 5 de enero de 2012. Aceptado: 5 de marzo de 2012. 


\section{Bibliografía}

Abbagnano, Nicola, Diccionario de filosofía, trad. de Calderón, José Esteban, Fondo de Cultura Económica, México, 2007.

Basso, Domingo, Nacer y morir con dignidad, estudios de bioética contemporánea, Selare, Buenos Aires, 1990.

Brennan, Robert, Psicología Tomista, trad. de Villacorta, Efrén, Aguilar, Madrid, 1959.

Callahan, David, Poner límites, los fines de la medicina en una sociedad que envejece, trad. de Mauri Mas, Assumpta, Triacastela, Madrid, 2004.

CAmps, Victoria, Una vida de calidad, Ares y Mares, Barcelona, 2001.

Carrasco, María, «Adam Smith y el relativismo», Anuario filosófico, 47-1, pp. 179-204.

Deferrari, Roy, A Lexicon of St. Thomas Aquinas, CUA Press, Washington, 1947.

García López, José, Los derechos humanos en Santo Tomás de Aquino, Eunsa, Pamplona, 1979.

JABARES, MARIO, «El valor de la vida humana. Una aproximación desde la Antropología», Studium, 49-1, pp. 41-76.

LeClerCQ, JACQues, La philosophie morale de Saint Thomas devant la pensée contemporaine, J. Vrin, Paris, 1955.

Lolas, Fernando (ed.), Dimensiones éticas de las regulaciones de salud, CBIED, Santiago, 2009.

Lukac De Stier, María, «Hombre: ni ángel, ni bestia», Cuadernillos de la Sociedad Tomista Argentina, $32^{\circ}$ Semana Tomista, pp. 1-9.

Martínez, JoAn, «Forma dat esse come principio fondamentale dell'ontologia della persona di Tommaso d'Aquino», Angelicum, 86-3, pp. 669-688.

Melendo, Tomás, Dignidad humana y bioética, Eunsa, Pamplona, 1999.

Meinvielle, Julio, Crítica de la concepción de Maritain sobre la persona humana, Epheta, Buenos Aires, 1993. 
Molinaro, Aniceto, «Riflessioni sulla Dignitatis humanae», Gregorianum, 89-4, pp. 806820.

Palazzani, Laura, «Metafisica e bioetica: il concetto di persona?», Aquinas, 50-1, pp. 153-161.

Pontificium Concilium P. L., La dignidad del anciano y su misión en la Iglesia y en el mundo, Ciudad del Vaticano, 1998.

Thomae Aquinatis, In decem libros Ethicorum Aristotelis ad Nicomachum Expositio, Marietti, Romae, 1949.

------------------------, In libros Politicorum Aristotelis Expositio, Marietti, Romae, 1951.

Tomás De Aquino Suma Teológica, Obras completas, traducción y notas de Barbado Viejo, Francisco, edición bilingüe, BAC, Madrid, 1957.

, Suma Contra Gentiles, Obra completa, traducción y notas Robles Carcedo, Laureano OP y Robles Sierra, Adolfo OP, edición bilingüe, BAC, Madrid, 1967.

Torrell, Jean-Pierre, Tommaso D'Aquino, l'uomo e il teologo, Edizioni Piemme Theologica, Roma, 1994.

Ugarte, José, El derecho de la vida, el derecho a la vida Bioética y Derecho, Editorial Jurídica de Chile, Santiago, 2006.

Widow, José Luis, Introducción a la ética, Globo, Santiago, 2009. 